\title{
A MORPHOLOGICAL STUDY ON PATTERNS OF HUMAN CALCANEAL ARTICULAR FACETS FOR TALUS IN POPULATION OF BIHAR AND ITS CLINICAL IMPLICATIONS
}

\author{
Sanjay Kumar1, Ashok Kumar Singh², Nafees Fatima3 ${ }^{3}$ Md. Jawed Akhtar ${ }^{4}$, Ruchi Ratnesh ${ }^{5}$, Vinod Kumar 6 \\ ${ }^{1}$ Senior Resident, Department of Anatomy, Indira Gandhi Institute of Medical Sciences, Sheikhpura, Patna, Bihar. \\ ${ }^{2}$ Associate Professor, Department of Anatomy, Vardhman Institute of Medical Sciences, Pawapuri, Nalanda, Bihar. \\ ${ }^{3}$ Senior Resident, Department of Anatomy, Indira Gandhi Institute of Medical Sciences, Sheikhpura, Patna, Bihar. \\ ${ }^{4}$ Assistant Professor, Department of Anatomy, Indira Gandhi Institute of Medical Sciences, Sheikhpura, Patna, Bihar. \\ ${ }^{5}$ Senior Resident, Department of Anatomy, Indira Gandhi Institute of Medical Sciences, Sheikhpura, Patna, Bihar. \\ ${ }^{6}$ Professor and HOD, Department of Anatomy, Indira Gandhi Institute of Medical Sciences, Sheikhpura, Patna, Bihar.
}

ABSTRACT

\section{BACKGROUND}

The calcaneum is the largest and strongest bone of all tarsal bones. It articulates above with talus to form talocalcaneal joint. In the middle third of superior surface, there is an oval shaped posterior articular facet which articulates with the body of talus. In the anterior third of superior surface, there are anterior and middle facets for the articulation of head of talus.

Aim of the present study is to determine the variations of articular facets in population of Bihar and its clinical implications.

\section{MATERIALS AND METHODS}

This is a descriptive study which was conducted on human calcaneal articular facets in the Department of Anatomy from September 2016 to May 2017. 200 dry adults' human calcanei were obtained from Indira Gandhi Institute of Medical Science, Patna; Vardhman Institute of Medical Sciences, Pawapuri; Nalanda \& Darbhanga Medical College, Laheriasarai; and also from undergraduate students.

\section{RESULTS}

In this study, we found the 3 major types based on the separation of articular facets on superior surface i.e. type A, B \& C. In this study, type B was most common (54\%) in which Type B1 was commonest with fused anterior and middle facets without constriction. Type $\mathrm{C}$ was rarest variety of pattern.

\section{CONCLUSION}

This study reveals that configuration of articular facets influences the stability of subtalar joint.

\section{KEYWORDS}

Calcaneum, Facets for the Talus, Pattern, Variation.

HOW TO CITE THIS ARTICLE: Kumar S, Singh AK, Fatima N, et al. A morphological study on patterns of human calcaneal articular facets for talus in population of Bihar and its clinical implications. J. Evolution Med. Dent. Sci. 2017;6(56):4193-4196, DOI: 10.14260/Jemds/2017/908

\section{BACKGROUND \\ The calcaneum is the largest and strongest of all the tarsal bones. It is the most proximal of all the tarsal bones and situated below the talus and extends behind it. It is directed upwards, forwards and laterally. It is somewhat irregular cuboid in shape. It is the weightbearing bone. The superior surface of calcaneum has two parts- non-articular and articular. The non-articular part extends posteriorly and is about one third of total superior surface. Anterior to this non- articular part is articular which articulates with talus bone to form talocalcaneal joint, where inversion and eversion of foot occurs.[1]}

Financial or Other, Competing Interest: None.

Submission 05-06-2017, Peer Review 02-07-2017,

Acceptance 07-07-2017, Published 13-07-2017.

Corresponding Author:

Dr. Md. Jawed Akhtar

Assistant Professor,

Department of Anatomy,

Indira Gandhi Institute of Medical Sciences,

Sheikhpura, Patna,

Bihar, India.

E-mail: drjawed2k@gmail.com

DOI: $10.14260 /$ jemds $/ 2017 / 908$
Normally there are three articular facets on the superior surface of calcaneum for the articulation of talus boneanterior, middle and posterior facets. In the middle third of superior surface of calcaneum, there is an oval shaped posterior facet which articulates with the body of talus. In the anterior one third of superior surface of calcaneum there are two articular facets- anterior and middle for the articulation of head of talus. ${ }^{[2]}$ The posterior calcaneal facet for talus does not show much variation. ${ }^{[3]}$ But there are considerable variations in the patterns of anterior and middle articular facets in different races.[4] There are several studies on different population groups which also confirm the variations in the pattern of articular facets. ${ }^{[5-7]}$ These facet patterns are present in foetal calcanei and not a developmental response to physical activities. These morphological variations of calcaneal facets may predispose to the development of arthritic changes in the subtalar joint. [8] Variations in the talar facets of calcanei are important because they influence subtalar joint stability. Knowledge about the variations in talar facets of calcanei is essential for orthopaedic surgeons while correcting foot deformities. Therefore, this study was carried out after finding a scarcity of data on the variations of the calcaneal facets for the talus in the population of Bihar. 
Calcaneum is also a useful tool for determination of sex and is long being considered useful in stature estimation. ${ }^{99,10,11,12]}$ The objective of the present study was to identify the patterns of the talar facets of calcanei and their clinical implication. Data of this study compared with those of previous studies.

\section{MATERIALS AND METHODS}

This is a descriptive study which was conducted on human calcaneal articular facets in the Department of Anatomy from September 2016 to May 2017. 200 human calcaneum dried bones obtained from Department of Anatomy \& Department of Forensic Medicine of Indira Gandhi Institute of Medical Science, Patna; Vardhman Institute of Medical Sciences, Pawapuri; Nalanda \& Darbhanga Medical College, Laheriasarai; and also from undergraduate students. Adult bones irrespective of sex were included in my study. Calcaneal bones with prominent pathological changes or damaged bones were excluded. The patterns of articular facets on superior surface of calcaneum were observed with naked eye and by using hand lens. A sliding Vernier calliper of $0.1 \mathrm{~mm}$ accuracy was used for measuring distance between articular facets. Data obtained from bones were analysed for patterns of talar articulating facets and were compared with those of previous studies.

3 types of patterns of talar facets in calcanei were considered-

Type A- Anterior, middle and posterior articular facets separate with 4 subtypes (A1, A2, A3, A4).

A1- Distance between anterior and middle articular facets $<2 \mathrm{~mm}$.
A2-

Distance between anterior and middle articular facets $2-5 \mathrm{~mm}$.

A3- Distance between anterior and middle articular facets $>5 \mathrm{~mm}$

A4- There is only one joint facet named as anterior talar facet.

Type B- Anterior and middle facets fused with 2 subtypes (B1, B2).

B1- There was a constriction between anterior and middle facets.

B2- There was no constriction between anterior and middle facet.

Type C- Anterior, middle and posterior facets fused.

\section{RESULTS}

In this study, we found 3 major types based on the separation of articular facets on superior surface i.e. type A, B \& C. Type B1 with fused anterior and middle facets without constriction was the most common pattern of articular facet.

In the present study, type A was found in 90 calcanei (45\%) out of which A1 was in 10 calcanei (5\%) (5 right and 5 left), A2 was in 30 calcanei (15\%) (14 right and 16 left), A3 was seen in 40 calcanei (20\%) (22 right and 18 left); A4 were seen in 10 calcanei (5\%) (5 right and 5 left).

Type B was found in 108 calcanei (54\%), out of which B1 was found in 44 calcanei (22\%) (21 right and 23 left); B2 was found in 64 calcanei (32\%) (32 right and 32 left). In type C, all the 3 facets were fused.

Type C found in 2 calcanei (1\%) (1 right and 1 left).

\begin{tabular}{|c|c|c|c|c|c|c|}
\hline Sl. No. & Type & Sub Type & Right (\%) & Left (\%) & \multicolumn{2}{|c|}{ Total (\%) } \\
\hline \multirow{4}{*}{1} & \multirow{4}{*}{ A } & $\mathrm{A} 1$ & $5(2.5 \%)$ & $5(2.5 \%)$ & $10(5 \%)$ & \multirow{4}{*}{$90(45 \%)$} \\
\hline & & $\mathrm{A} 2$ & $14(7 \%)$ & $16(8 \%)$ & $30(15 \%)$ & \\
\hline & & $\mathrm{A} 3$ & $22(11 \%)$ & $18(9 \%)$ & $40(20 \%)$ & \\
\hline & & $\mathrm{A} 4$ & $5(2.5 \%)$ & $5(2.5 \%)$ & $10(5 \%)$ & \\
\hline \multirow{2}{*}{2} & \multirow{2}{*}{ B } & B1 & $21(10.5 \%)$ & $23(11.5 \%)$ & $44(22 \%)$ & \multirow{2}{*}{$108(54 \%)$} \\
\hline & & B2 & $32(16 \%)$ & $32(16 \%)$ & $64(32 \%)$ & \\
\hline 3 & \multicolumn{2}{|c|}{$\mathrm{C}$} & $1(0.5 \%)$ & $1(0.5 \%)$ & $2(1 \%)$ & $2(1 \%)$ \\
\hline \multicolumn{3}{|c|}{ Total } & $100(50 \%)$ & $100(50 \%)$ & $200(100 \%)$ & \\
\hline
\end{tabular}

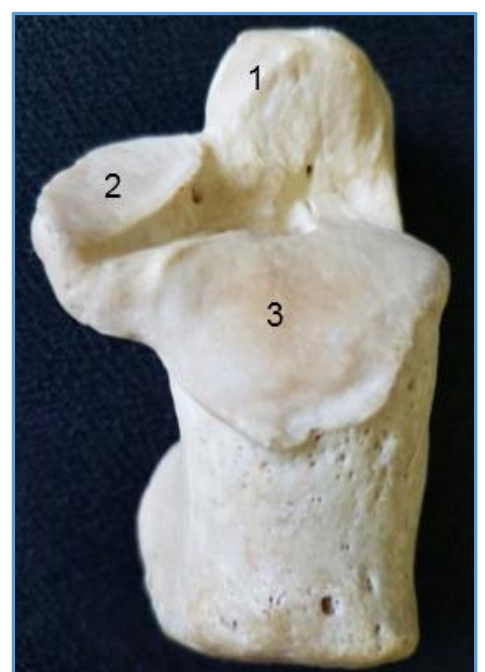

Figure 1. All Three Facets are Separated [1- Anterior Facet, 2-Middle Facet, 3-Posterior Facet]

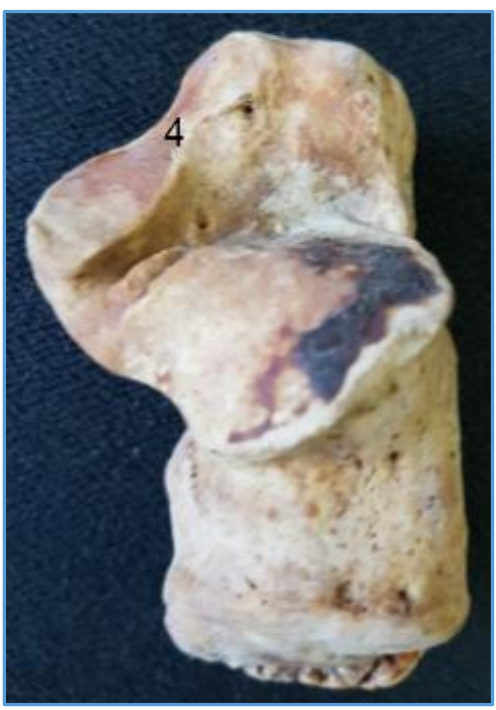

Figure 2. Anterior and Middle Facets Fused (constricted) [4- Fused and Constricted Anterior and Middle Facets] 


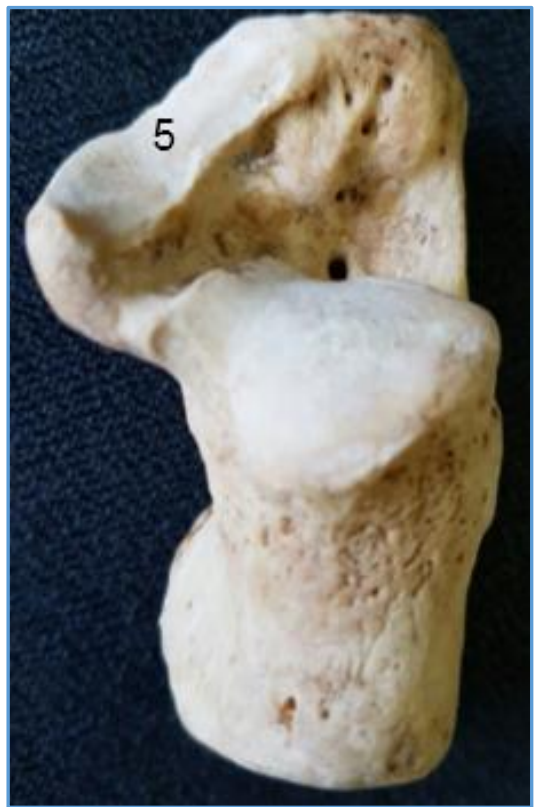

Figure 3. Anterior and Middle Facets Fused (Uniform) [5- Fused and Uniform Anterior and Middle Facets]

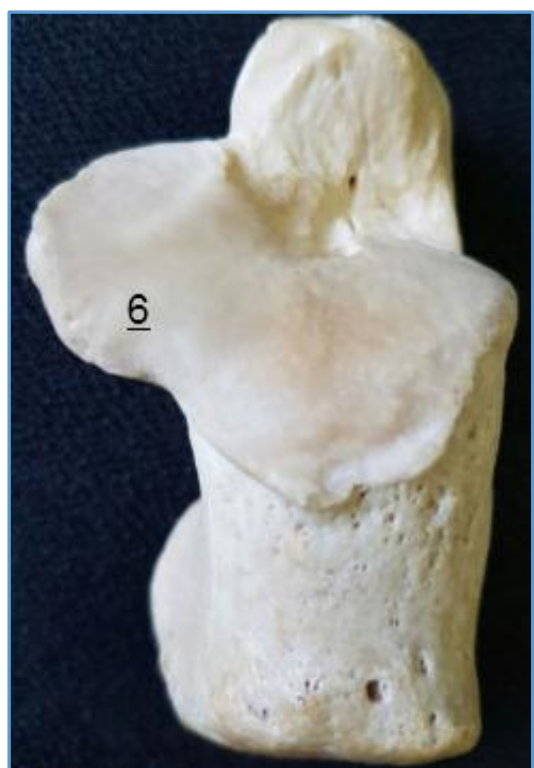

Figure 4. Middle and Posterior Facets Fused [6-Fused Middle and Posterior Facets]

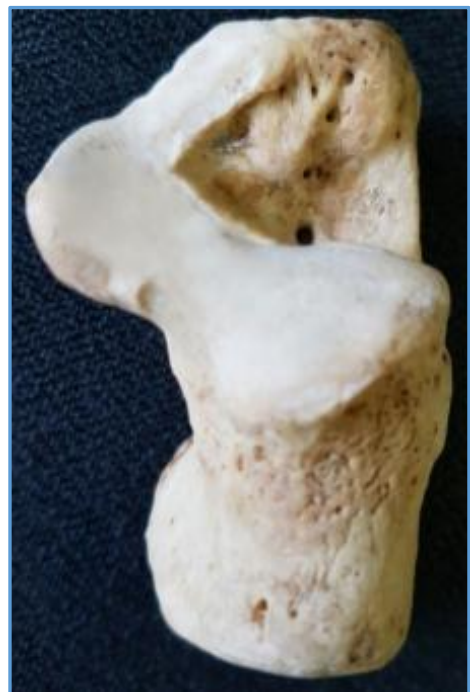

Figure 5. All Three Facets Fused to Form Single Facet

\section{DISCUSSION}

From the table no. 2, it is evident that the result of this study is very close to other Indian $[9,13,14]$ and African studies. ${ }^{[7,15]}$ In this study, I found that type B (54\%) is the most common pattern of talar facets of calcanei. Type A pattern [45\%] next common and type $\mathrm{C}$ [1\%] is very rare pattern of talar articular facet of calcanei. Among the type B pattern, B2 subtype (32\%) is commonest. High incidence of type A was found in one study in Africans.[16] Type A is more common than type B in American population.[10] El-Eishi found subtype A4 to a greater extent in Egyptians which suggests that the facets are genetically determined as mentioned by Brunning and Barnett.[8,17]

Type A pattern of facet forms more stable joint than type B. ${ }^{[10,18]}$ Less medial rotation of talar head occurs in type B facet pattern leading to unstable subtalar joint and causes osteoarthritis.[10]

The interval between anterior and middle facets are important in osteotomy and interposition bone grafting to correct the deformities of pes planus. In this procedure, the identification of the interval between the anterior and middle facets is important for the exact placement of retractor because the line of osteotomy passes through this interval.[19,20] This technique is suitable for Europeans who predominantly have calcanei with type A pattern (with separate anterior and middle facets). So awareness about the variations in talar facets of calcanei is important during surgical management of foot deformities. In Indian population, type B (fused anterior and middle facets) was common, so orthopaedic surgeons should be careful or a suitable modification of technique is required.

Knowledge of variations in the morphology on articular facets of calcaneum is very important in triple arthrodesis procedure for flat foot deformities.

\begin{tabular}{|c|c|c|c|c|c|c|c|c|c|c|c|}
\hline Sl. No. & Study, Year & T & A & A1 & A2 & A3 & A4 & B & B1 & B2 & C \\
\hline 1 & Brunning and Barnett (1963) Indian & 78 & 22 & & & & & 56 & & & \\
\hline 2 & Jha and Singh (1972) Indian & 800 & 294 & & & & & 504 & & & 2 \\
\hline 3 & Gupta et al (1977) Indian & 401 & 31 & 9 & 4 & 13 & 5 & 67 & 28 & 39 & 2 \\
\hline 4 & Boonruangsri et al, (1992) Northeastern Thai & 230 & 40 & 11 & 19 & 8 & 2 & 59 & 19 & 40 & 0.43 \\
\hline 5 & Uygur et al (2009) Turkish race & & 39.3 & 4 & 13 & 17 & 5 & 58 & 25 & 33 & 22 \\
\hline 6 & Present study (2017) Indian & 200 & $45 \%$ & $5 \%$ & $15 \%$ & $20 \%$ & $5 \%$ & $54 \%$ & $22 \%$ & $32 \%$ & $1 \%$ \\
\hline
\end{tabular}




\section{CONCLUSION}

In the present study, the data collected from 200 normal dry calcaneal bones from Bihar in the northern part of India were analysed and compared with those of previous studies of different races. In this study, type B facet configuration is most common and type A configuration next common. These racial differences in patterns of talar articular facets for calcanei were probably genetically determined and not a developmental response to physical activities. This knowledge on the racial differences is very important for orthopaedic surgeons in India while correcting foot deformity. Less medial rotation of talar head occurs in type B pattern of articular facet leading to unstable subtalar joint and causes osteoarthritis.

\section{ACKNOWLEDGEMENT}

We sincerely thank Dr. Arvind Prasad, Principal \& HOD of Department of Forensic Medicine and Toxicology, IGIMS Patna for granting the permission to carry out the study in his department.

\section{REFERENCES}

[1] Moore KL. Clinically oriented Anatomy. $3^{\text {rd }}$ edn. Williams and Wilkins Baltimore 1992:490-1.

[2] Ranganathan TS. Lower limb. In: A textbook of human anatomy. $6^{\text {th }}$ edn. New Delhi: S. Chand, company Ltd 2002:P 235.

[3] Warwick R, Williams PL. Gray's anatomy. 35th edn. Edinburg: Longman Group Ltd 1973:P 377.

[4] Williams PL. Skeletal system. In: Gray's anatomy - the anatomical basis of medicine and surgery. $38^{\text {th }}$ edn. Edinburg: Churchill Livingstone 1995:P 715.

[5] Bunning PSC, Barnett CH. Variations in the talocalcaneal articulations. Journal of Anatomy 1963;97(5):643.

[6] Brunning PSC, Barnett CH. A comparison of adult and foetal talocalcaneal articulations. Journal of Anatomy 1965;99(1):71-6.

[7] Gupta SC, Gupta CD, Arora AK. Pattern of the talar articular facets in Indian calcanei. Journal of Anatomy 1977;124(3):651-5.
[8] Franune DV. Arthritis of the subtalar joint associated with sustentaculum tali facet configuration. J Anat 1993;183(3):631-4.

[9] Steele DG. The estimation of sex on the basis of the talus and calcaneus. Am J phys Anthropol 1976;45(3 pt 2):581-8.

[10] Bidmos MA, Asala SA. Sexual dimorphism of the calcaneus of South African blacks. J Forensic Sci 2004;49(3):446-50.

[11] Bidmos MA, Asala SA. Discriminant function sexing of the calcaneus of the South African whites. J Forensic Sci 2003;48(6):1213-8.

[12] Bidmos M, Asala S. Calcaneal measurement in estimation of stature of South African blacks. Am J Phys Anthropol 2005;126(3):335-42.

[13] Priya R, Manjunath KV, Balasubramanyam V. Variations of the talar articular facets of calcaneus in south Indian. South Asian Anthropologist 2006;6(1):69-71.

[14] Muthukumaravel N, Ramchandran D, Rajendran MS. Human calcaneal facets for the talus: patterns and clinical implications. JCDR 2011;5(4):791-4.

[15] Saadeh FA, Faud AH, Mahmoud SMI, et al. Patterns of the talar articular facets of Egyptian calcanei. JASI 2000;49(1):6-8.

[16] Bidmos M. Metrical and non-metrical assessment of population affinity from the calcaneus. Forensic Sci Int 2006;159(1):6-13.

[17] Eishi EH. Variations in the talar articular facets in Egyptian calcanei. Acta Anat 1974;89:134-8.

[18] Bruckner J. Variations in the human subtalar joint. J Arthrop and sports phys Ther 1987;8(10):489-94.

[19] Hyer CF, Lee T, Block AJ, et al. Evaluation of the anterior and middle talocalcaneal articular facets and the Evans osteology. J Foot and Ankle Surg 2002;41(6):389-92.

[20] Richardson GE. Pes planus. In: Terrycanale S. Campbell's operative orthopaedics. 9th edn. St Louis Mosby-Year Book, Inc 1998:1720-5. 